\title{
Safety Effects of Road Geometry and Roadside Features on Low-Volume Roads in Oregon
}

\section{Authors: Levi Ewan, Ahmed Al-Kaisy, and Fahmid Hossain}

This is a postprint of an article that originally appeared in Transportation Research Record. The final version can be found at https://doi.org/10.3141/2580-06.

Ewan, Levi, Ahmed Al-Kaisy, and Fahmid Hossain. "Safety Effects of Road Geometry and Roadside Features on Low-Volume Roads in Oregon." Transportation Research Record: Journal of the Transportation Research Board 2580, no. 1 (January 2016): 47-55. doi:10.3141/2580-06. 
Safety Effects of Road Geometry and Roadside Features on Low-Volume Roads

\author{
Levi Ewan, P.E. * \\ Research Engineer \\ Western Transportation Institute \\ Montana State University \\ Bozeman, MT 59717 \\ Phone: (406) 994-6127 \\ Fax: (406) 994-1697 \\ levi.ewan@coe.montana.edu
}

\author{
Ahmed Al-Kaisy, Ph.D. P.E. \\ Professor, Civil Engineering Department \\ Program Manager, Safety and Operations \\ Western Transportation Institute \\ Montana State University \\ PO Box 174250 \\ Bozeman, MT 59717 \\ Phone: (406) 994-6116 \\ Fax: (406) 994-6105 \\ aalkaisy@coe.montana.edu
}

\title{
Fahmid Hossain
}

Graduate Research Assistant

Western Transportation Institute

Montana State University

PO Box 174250

Bozeman, MT 59717

Phone: (406) 994-6114

Fax: (406) 994-1697

* Corresponding Author

Word Count: 5,031 words, 3 tables and 5 figures, 7,031 total word equivalent 


\begin{abstract}
Crashes are random events and can occur at any location along the roadway. On roadways with higher traffic volumes, the more frequent occurrence of crashes allows for the direct identification of high crash locations using historical data. On low volume roads, crash occurrence, particularly fatal and serious injury crashes, is less frequent. There is a need to better understand the different risks associated with geometric and roadside features along low volume roadways in order to identify locations where countermeasures may be employed to proactively address crashes before they occur. This article describes the data collection and analysis of a large sample of low-volume roads in Oregon to quantify the effects of geometric and roadside features on crash occurrence and associated risks. The effects of lane width, shoulder width, grade, side slope, fixed objects near the roadway, and horizontal and vertical curves have been quantified. For the low volume road sample, lanes less than 12 feet have a much higher crash risk than roads with the standard 12-feet lanes. Similarly, roads with narrow or no shoulders tend to have much higher crash rates than roads with 4- or 5-ft shoulders. Crash risk is shown to be much higher on curves with higher degrees of curvature compared to curves with smaller degrees of curvature.
\end{abstract}

Keywords: risk factors, geometry, roadside features, low-volume roads 


\section{INTRODUCTION}

Motor vehicle transportation is a necessary yet somewhat risky part of most U.S. residents' daily lives. Crashes that occur on U.S. roadways have enormous economic and social impacts. In 2013, 32,719 lives were lost due to motor vehicle crashes corresponding to an overall rate of 1.09 fatalities per 100 million vehicle miles traveled (VMT) (1). Rural roads that tend to experience lower traffic volumes are often constructed and maintained to lower standards than higher volume roads. Lack of shoulders, narrower lanes, more and sharper curves, and less forgiving roadsides are encountered more often on low-volume roads compared to well-travelled facilities. These less than ideal features are thought to contribute to higher crash risk and severity. Evidence for this can be seen by examining data from the National Highway Traffic Safety Administration (NHTSA) and the U.S. Department of Transportation (USDOT) to determine fatalities rates (per 100-million VMT) by road classification $(2,3)$. Table 1 shows the fatality rates for urban and rural roads by facility classification.

TABLE 1 National Fatality Rate (per 100-Million VMT) by Road Classification (2013 Data)

\begin{tabular}{|c|c|c|c|c|}
\hline & Class & Fatalities & VMT (Billions) & Rate \\
\hline \multirow{5}{*}{ 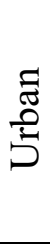 } & Total & 14,987 & $2,046.41$ & 0.73 \\
\hline & Interstate & 2,088 & 505.31 & 0.41 \\
\hline & Other Arterial & 8,550 & $1,068.93$ & 0.80 \\
\hline & Collector & 1,101 & 188.55 & 0.58 \\
\hline & Local & 3,231 & 283.63 & 1.14 \\
\hline \multirow{5}{*}{ 奈 } & Total & 17,696 & 941.91 & 1.88 \\
\hline & Interstate & 1,992 & 234.30 & 0.85 \\
\hline & Other Arterial & 7,388 & 358.76 & 2.06 \\
\hline & Collector & 4,744 & 221.22 & 2.14 \\
\hline & Local & 3,469 & 127.62 & 2.72 \\
\hline
\end{tabular}

From Table 1 it is evident that the road classes that typically experience lower traffic volumes (i.e. rural collector and rural local) tend to have the highest fatality rates. This study focuses on these low-volume roads and examines the crash risk effects of various geometric and roadside features through analyses using extensive road and safety data from a large sample of Oregon's low volume roads.

\section{BACKGROUND}

A number of studies have been performed over the years attempting to understand and quantify the effect of roadway geometry and roadside features on crash risk. Most of these studies have examined a mix of road characteristics in addition to traffic and crash data.

Researchers in New Zealand used data on horizontal curvature, superelevation, grade, pavement roughness, rutting, texture and skid resistance for approximately 13,670 lane-miles of roadway with the ultimate goal to develop a crash prediction model (4). The study sample included all paved roadways in New Zealand. This data along with traffic volume data and crash data were compiled over five years and descriptive statistics and regression model analyses were performed to determine critical variables. Horizontal curvature and skid resistance were found to have strong effects on crash rates. 
In Virginia, researchers compiled crash, speed, and traffic data in addition to curvature, grade, and other descriptive roadway information (e.g. signage, school zones, railroad crossings, passing zones) in an effort to determine causal factors for crashes on urban and rural two-lane highways (5). Four years of data were used in the study of 143 five-to-ten mile segments of road. Fault-tree analysis and generalized linear models were used to identify crash causal factors. Horizontal curvature and traffic volume were found to be the significant causal factors for the most common crash type (i.e. run-off-the-road).

Using data from Pennsylvania and Washington State, researchers set out to determine the safety effects of different lane and shoulder widths and how these variables are inter-related for a given fixed pavement width on rural two-lane roads (6). The data included more than 52,000 miles of pavement and shoulder width data, traffic volumes, and 5 years of crash data. Overall, crash risks were found to be lower for wider total pavement widths as well as wider lanes (holding shoulder width constant) and wider shoulders (holding lane width constant). For a fixed total pavement width the trade-offs between lane and shoulder widths were not obviously in favor of one versus. the other. For certain pavement widths wider lanes were superior to wider shoulders, but vice-versa for other pavement width.

Researchers in Australia completed a comprehensive literature review of published studies on the effects of geometry and roadside features on crash risk in 2010 (7). It was found that total pavement width had a large effect on crash risk for rural two-lane roads, with 5.5 meter total pavement width being 2.7 times more likely to experience a crash than a 10 meter pavement width. Also smaller radii curves, especially those under 400 meters, have substantially higher crash risks than larger radii curves. Steeper vertical grades had minor crash risk increases up to approximately $6 \%$ and larger increases for grades over $6 \%$ compared to flat roadways. Adequate clear-zones and guardrails were also found to be beneficial, especially for reducing the severity of run-off-the-road crashes.

In Texas researchers investigated the effect of roadside features on two-lane rural road departure crashes (8). In this study 245 miles of two-lane rural roads were sampled to collect shoulder width, side slope rating, driveway density, and lateral clearance for analysis with traffic data and six years of crash history. For the analysis, a negative binomial model for crash frequency was used as well as multinomial logit model for crash severity. Larger lateral clearances and shoulder widths were both found to have fewer and less severe road departure crashes. Steeper side slope ratings were found to correspond to more and more severe road departure crashes. Driveway density did not appear to have much influence on crash occurrence or severity.

Additional studies that have examined two-lane roads have found similar conclusions as the studies detailed above $(9,10,11,12)$. Horizontal curvature, lane and shoulder widths, pavement condition, and clear zone characteristics have all been documented to effect crash risk at varying degrees. This research effort aims to add to the knowledge base that has begun to be constructed by these studies while focusing on low-volume two-lane roads using extensive data and a large sample with many road characteristics.

\section{OBJECTIVE}

The objective of this research is to quantify the crash risks along low-volume two-lane roads in Oregon as related to roadway geometry and roadside characteristics such as lane width, shoulder width, grade, side slope, fixed objects in the clear zone, driveway density, and horizontal and vertical curves. Since low-volume roads tend to have a lower frequency of crashes due to low traffic volumes, identifying crash "hot-spots" is not always possible. Efforts like this one, which 
may establish the relationship between existing road geometry, roadside features, and crash risk may then be used as a proactive means to identify risky areas that might not be obvious from crash histories alone. This effort will establish these many relationships for more rural, remote, low volume areas which may differ from the relationships found for these features on more welltraveled roadways.

\section{DATA COLLECTION}

The focus of this research is low-volume roads in Oregon. Roads with annual average daily traffic (AADT) of 1,000 vehicles per day or less were chosen to represent "low-volume" roads. A total sample target of approximately 600 - 800 miles was deemed appropriate to ensure large geographic coverage while recognizing the labor and cost limitations that the extensive data collection effort would require. State owned roads were used because the required data was available for these routes, and was not as readily available for roads at the county level. Two distinct regions were defined in Oregon: Western Oregon and Eastern Oregon. The roads in these two regions are somewhat different due to the geographic differences in terrain between the rainy, mountainous and winding roads included in the west and the drier, flatter and straighter roads in the east.

All state owned roads with AADT less than or equal to $1,000 \mathrm{vpd}$ were queried using online GIS data, and then random selections were made from that query to arrive at the target amount of road sample. The original sample is comprised of a total of 831.75 miles of road (435.55 miles western, 396.20 miles eastern). A 680.85 mile analysis sample (323.7.45 miles western, 357.15 miles eastern) was then used for road segment analysis. The analysis sample was compiled by removing intersection areas from the original sample as intersection specific crash risk considerations should involve different characteristics outside of the immediate scope of this effort. Intersection areas were considered to be the 0.05 mile segment which contained the intersection and the two, 0.05 mile segments on either side of the intersection-containing segment. The analysis sample is comprised of all $55 \mathrm{mph}$ posted speed limit road segments. Geometric and road characteristic data for these road segments were then collected, as well as 10 years of crash data and traffic volumes for these roadways. The most recently available ten years of crash data (2004-2013) were selected as this duration would provide an accurate representation of trends over time on each roadway. The same 10 years of AADT data were also collected.

Oregon Department of Transportation (ODOT) online databases and video logs were used to identify and compile roadway geometrics and roadside characteristics of interest for the sample. AADT, lane type and width, shoulder type and width, percent grade, driveway density, side slope rating, fixed objects near the roadway, guardrail presence, horizontal curve presence, degree of curvature, length of horizontal curve, spiral curve presence, vertical curve presence and type, and length of vertical curve were determined for the sample with 0.05 mile resolution. The 0.05 mile resolution was selected because that increment allowed for video log data to be comprehensive without missing characteristics of interest between video log images. The ten years of crash records from ODOT online databases were also gathered for the sample. Over 20 individual crash characteristics including crash location, road character, impact location, traffic control, crash type, crash severity and vehicle type involvement data were collected and combined with the geometric data into a unified database for analysis. The resulting comprehensive data set is very rich and includes all road characteristics described combined with all crash data for the 680.85 miles of low-volume state-owned roads in Oregon at 0.05 mile resolution. The database prepared for this purpose consists of over 13,000 records, each representing a 0.05 mile sub-segment with more than 60 individual road and crash characteristics associated with each 0.05 miles of sample. 
Most of the road characteristics gathered from ODOT databases required no interpretation and could be used as recorded by ODOT including lane type and width, shoulder type and width, AADT, grade, horizontal curve data (degree of curvature, length, spiral presence), and vertical curve data (type, length). Other data necessary for analysis required manual video log review and data entry. Driveway density, side slopes, amount of fixed objects present in the clear zone and guardrail presence were all recorded manually while reviewing video log images at 0.05 mile increments. Side slope ratings and fixed object ratings are somewhat subjective, requiring the data collector to assign values from video log images. Side slope ratings were characterized as 1 (flat), 2 (moderate), or 3 (steep). Fixed object ratings were 1 (few fixed objects in the clear zone), 2 (some), or 3 (many). Side slope and fixed object ratings were collected for each side of the roadway independently then averaged. The same data collector was used for recording both ratings for the entire sample to limit any variability that may have been introduced had multiple persons been used. All crash data gathered was used as recorded in the ODOT database, requiring no interpretation.

\section{ANALYSIS METHODS AND RESULTS}

Overall descriptive statistics, crash rate analyses, and multivariate regression and correlation analysis are used to determine how these road characteristics influence crash rate and severity. In order to understand overall road and crash characteristics for Oregon's low volume roads, descriptive statistics of the total road sample and crash population were compiled. The next step was to determine more detailed relationships between individual road characteristics and crashes. For this crash rates normalized by segment length and volume in the form of VMT were employed. Additionally crash proportions by crash severity, location relative to the roadway, crash type and vehicle involvement were analyzed. Lastly, multivariate linear regression and correlation analyses for crash rate and crash severity rate were also completed.

\section{Descriptive Statistics}

The following descriptive statistics define the overall road characteristics and crash history for the sample.

\section{Road Characteristics}

All 680.85 miles of roadway included in the segments sample are paved (over $99 \%$ of the pavement is asphalt), two-lane, two-way roads with posted speed limits of $55 \mathrm{mph}$. The lane and shoulder width proportions for the sample are shown in Figure 1. 


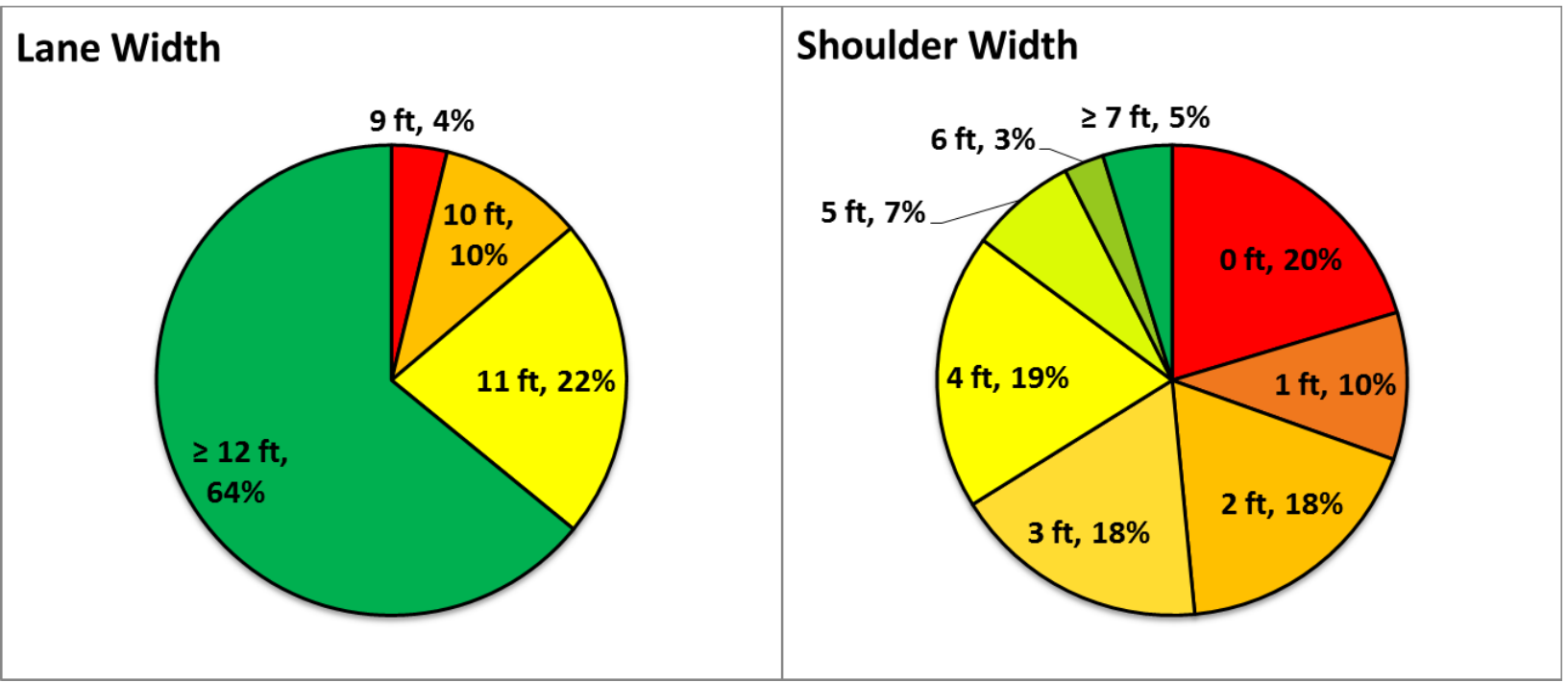

\section{Figure 1: Lane and Shoulder Widths}

Most of the sample (64\%) has lane width of 12 feet or greater, but much of the sample $(20 \%)$ has no shoulders. AADT categories from $<200 \mathrm{vpd}$ up to $900-1000 \mathrm{vpd}$ in $100 \mathrm{vpd}$ increments are distributed in a somewhat equal manner which is similar for driveway densities which range from 0 to $\geq 7$ driveways per mile in 1 driveway per mile increments. The most common "fixed objects in the clear zone rating" is few which comprises $66 \%$ of the sample. Side slope ratings are spread somewhat evenly across the categories: flat, moderate and steep. Degree of curvature for horizontal curves is distributed as shown in Figure 2.
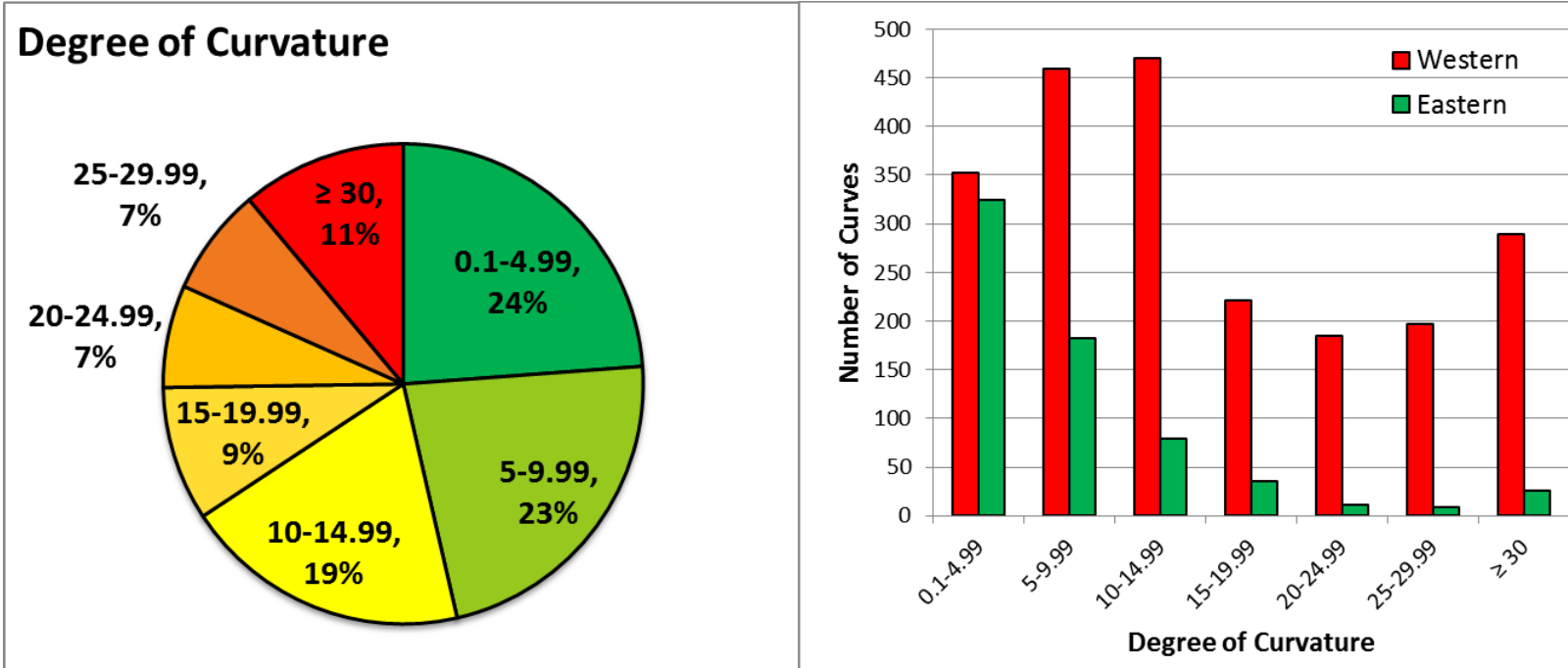

\section{Figure 2: Degree of Curvature}

Western Oregon curves are more numerous and are typically much sharper than the Eastern Oregon curves as evidenced by the larger number and greater proportions of Western curves in the higher degree of curvature categories.

Similarly the Western segments have more miles of road with grades steeper than $5 \%$, while most of the Eastern segments are on grades less than 1\% as shown in Figure 3. 


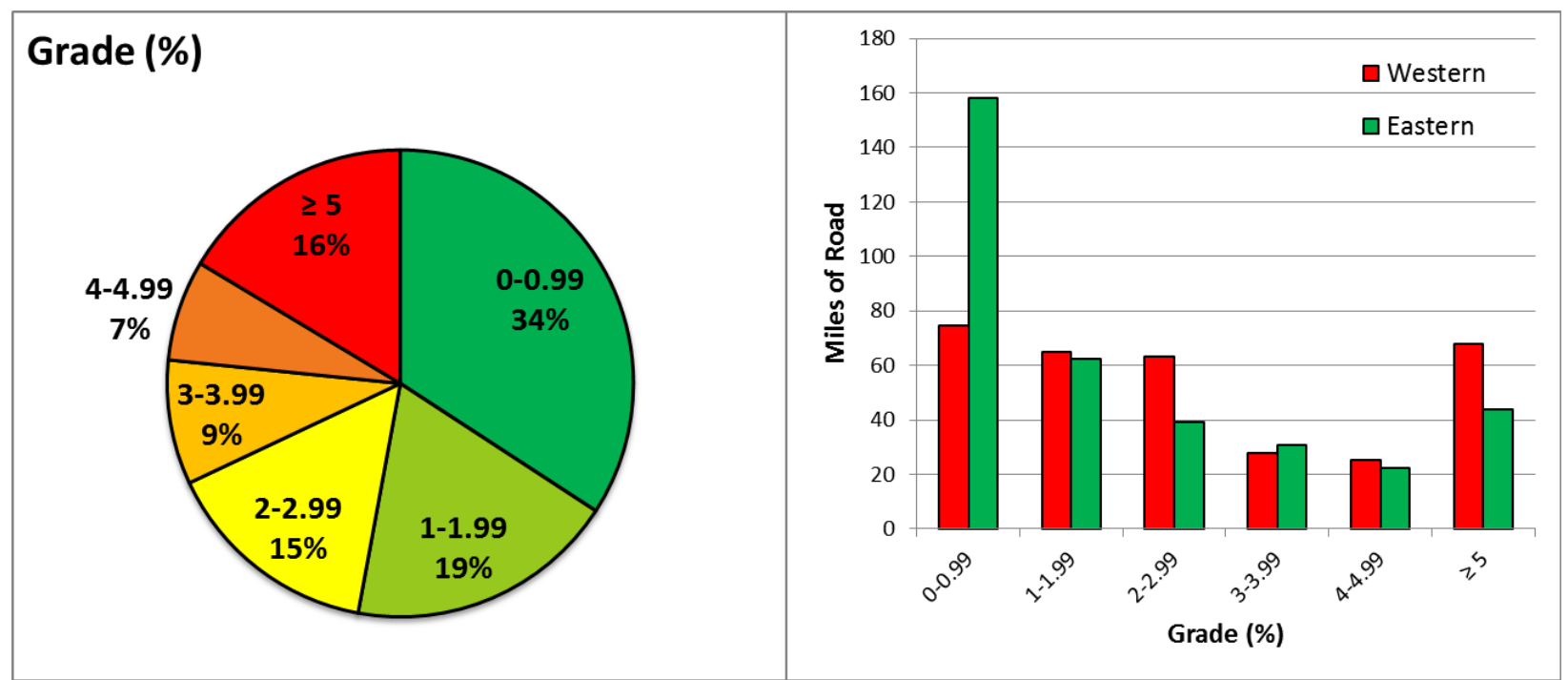

Figure 3: Vertical Grade

\section{Crash Characteristics}

A total of 1251 crashes occurred on the sample during the ten year study period. Figure 4 shows the proportions by crash type, vehicle involvement, crash severity and driver age. 


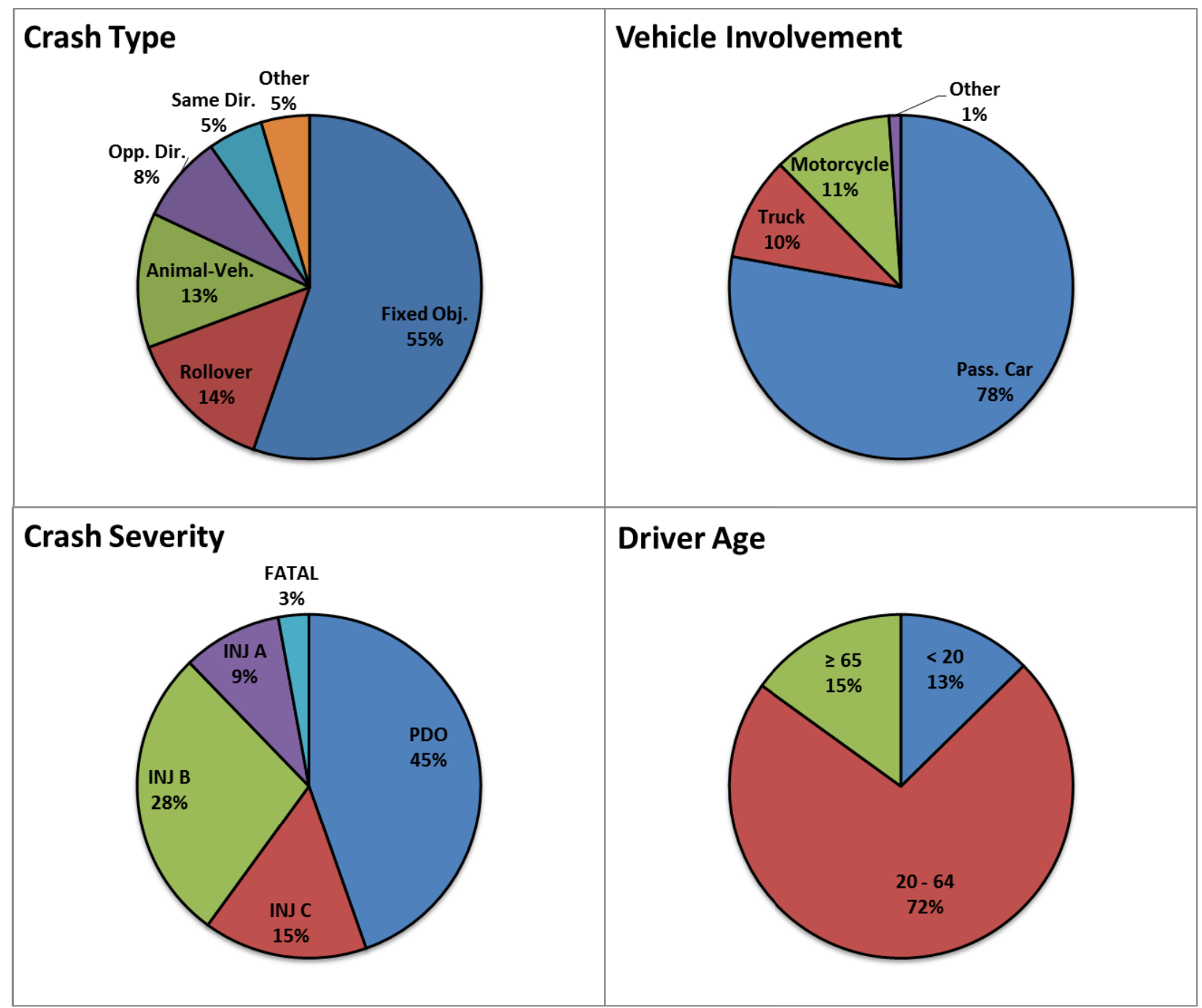

\section{Figure 4: Crash Characteristics}

The most common crash type for the sample was fixed-object crashes which comprised $55 \%$ of the sample. Seventy-eight (78\%) percent of crashes involved only passenger vehicles, $10 \%$ involved large trucks and 11\% involved motorcycles. Forty-five (45\%) percent of all crashes were property damage only (PDO) crashes, $15 \%$ were injury $\mathrm{C}$ (possible injury), $28 \%$ were injury $\mathrm{B}$ (non-incapacitating injury), 9\% were injury A (incapacitating injury), and 3\% were fatal crashes. Teen drivers made up $13 \%$ of the crash proportion, while drivers over 65 were involved in $15 \%$ of the sample crashes.

\section{Crash Rates}

Crash rates were calculated for road characteristics individually in this portion of the analysis to assess relative risk between road characteristic categories. Each individual road characteristic was split into logical categories and the traffic volumes and crashes for each characteristic category were used to calculate the crash rate (per million VMT) to observe the effect of a characteristic on crash occurrence. Figure 5 shows the crash rates for each road characteristic with shaded bars used to indicate when a category crash rate is based on a small sample size $(<5 \%$ of the relevant sample 
population). These values based on small sample size are less reliable than those based on larger samples. Table 2 shows the length of each category and number of crashes as well as the crash rates for each road characteristic. 

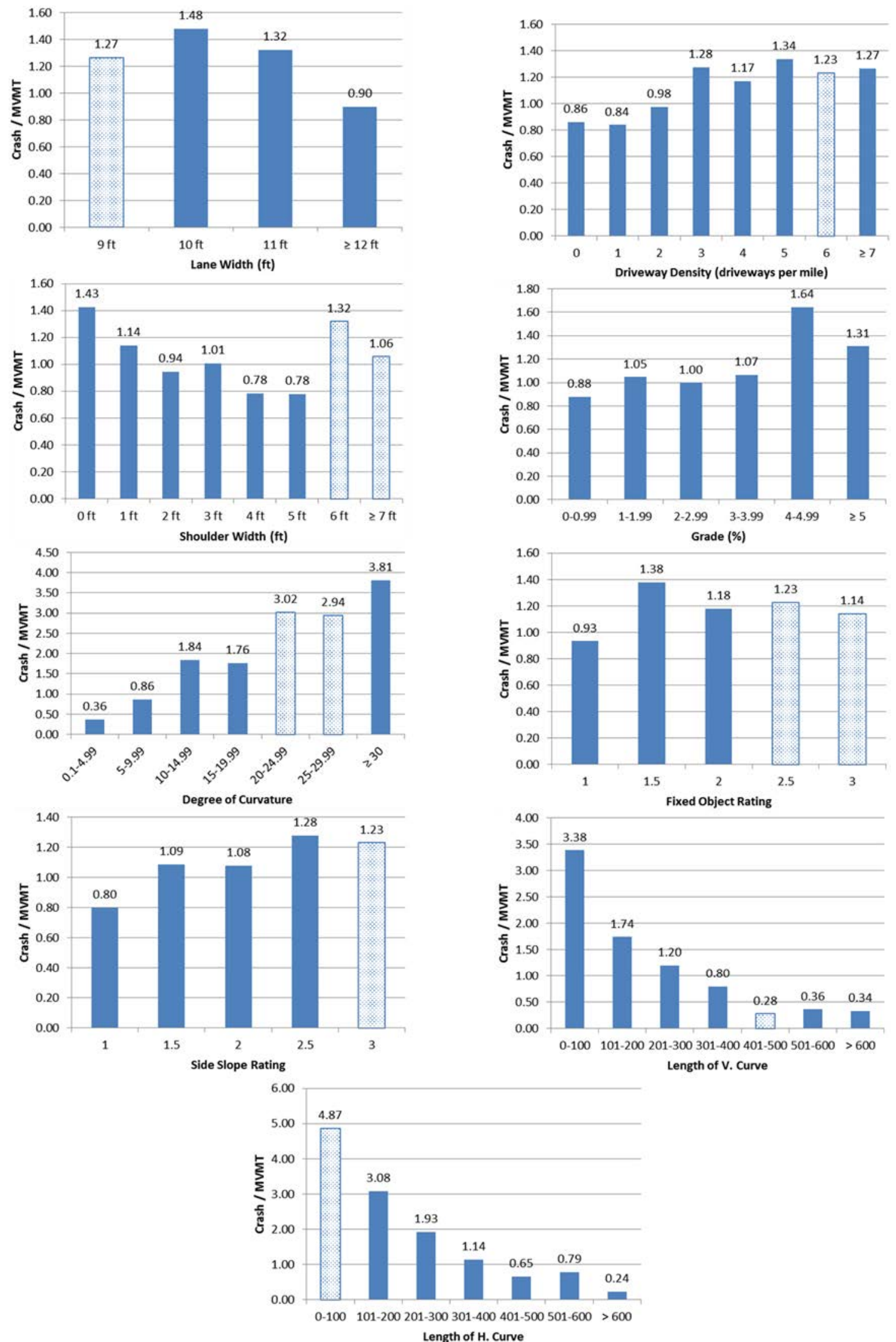

Figure 5: Crash Rates for Road Characteristics 
TABLE 2 Crash Rate for Road Characteristics

\begin{tabular}{|c|c|c|c|c|c|c|c|}
\hline & Miles & Crashes & $\begin{array}{l}\text { Rate per } \\
\text { MVMT }\end{array}$ & & Miles & Crashes & $\begin{array}{l}\text { Rate per } \\
\text { MVMT }\end{array}$ \\
\hline \multicolumn{4}{|c|}{------- Lane Width --------- } & \multicolumn{4}{|c|}{-------- Total Sample ---------- } \\
\hline $9 \mathrm{ft}$ & $* 26$ & 50 & $* 1.27$ & & $680.85 \mathrm{mi}$ & 1251 & 1.059 \\
\hline $10 \mathrm{ft}$ & 68 & 159 & 1.48 & & & & \\
\hline $11 \mathrm{ft}$ & 150 & 348 & 1.32 & & & & \\
\hline $12 \mathrm{ft}+$ & 436 & 694 & 0.90 & & & & \\
\hline & & & & & & & \\
\hline \multicolumn{4}{|c|}{---------- Shoulder Width ---------- } & \multicolumn{4}{|c|}{--------- Driveway Density ---------- } \\
\hline $0 \mathrm{ft}$ & 138 & 348 & 1.43 & 0 per mi & 123 & 174 & 0.86 \\
\hline $1 \mathrm{ft}$ & 69 & 181 & 1.14 & 1 per mi & 149 & 200 & 0.84 \\
\hline $2 \mathrm{ft}$ & 123 & 188 & 0.94 & 2 per mi & 122 & 196 & 0.98 \\
\hline $3 \mathrm{ft}$ & 120 & 178 & 1.01 & 3 per mi & 81 & 180 & 1.28 \\
\hline $4 \mathrm{ft}$ & 129 & 163 & 0.78 & 4 per mi & 53 & 111 & 1.17 \\
\hline $5 \mathrm{ft}$ & 50 & 65 & 0.78 & 5 per mi & 39 & 95 & 1.34 \\
\hline $6 \mathrm{ft}$ & $* 19$ & 49 & $* 1.32$ & 6 per mi & $* 30$ & 69 & $* 1.23$ \\
\hline $7 \mathrm{ft}+$ & $* 32$ & 79 & $* 1.06$ & 7 per mi+ & 85 & 226 & 1.27 \\
\hline & & & & & & & \\
\hline \multicolumn{4}{|c|}{--------- Degree of Curvature ---------- } & \multicolumn{4}{|c|}{---------- Grade $(\%)$---------- } \\
\hline$<5$ & 70 & 44 & 0.36 & $<1$ & 233 & 352 & 0.88 \\
\hline $5-10$ & 42 & 66 & 0.86 & $1-2$ & 127 & 240 & 1.05 \\
\hline $10-15$ & 28 & 95 & 1.84 & $2-3$ & 103 & 206 & 1.00 \\
\hline $15-20$ & 12 & 37 & 1.76 & $2-4$ & 59 & 100 & 1.07 \\
\hline $20-25$ & $* 7$ & 36 & $* 3.02$ & $4-5$ & 48 & 124 & 1.64 \\
\hline $25-30$ & $* 8$ & 38 & * 2.94 & $\geq 5$ & 112 & 229 & 1.31 \\
\hline$\geq 30$ & 10 & 59 & 3.82 & -- & -- & -- & -- \\
\hline & & & & & & & \\
\hline \multicolumn{4}{|c|}{--------- Side Slope Rating ---------- } & \multicolumn{4}{|c|}{--------- Fixed Object Rating ---------- } \\
\hline 1.0 & 131 & 173 & 0.80 & 1.0 & 455 & 688 & 0.93 \\
\hline 1.5 & 192 & 367 & 1.09 & 1.5 & 93 & 249 & 1.38 \\
\hline 2.0 & 268 & 487 & 1.08 & 2.0 & 85 & 195 & 1.18 \\
\hline 2.5 & 70 & 172 & 1.28 & 2.5 & $* 31$ & 76 & 1.23 \\
\hline 3.0 & $* 20$ & 52 & $* 1.23$ & 3.0 & $* 17$ & 43 & 1.14 \\
\hline \multicolumn{4}{|c|}{------- Length of Horizontal Curve (ft) ------- } & \multicolumn{4}{|c|}{------- Length of Vertical Curve (ft) ------- } \\
\hline $0-100$ & $* 4$ & 31 & $* 4.87$ & $0-100$ & 12 & 71 & 3.38 \\
\hline $100-200$ & 23 & 118 & 3.08 & $100-200$ & 36 & 105 & 1.74 \\
\hline $200-300$ & 32 & 111 & 1.93 & $200-300$ & 32 & 68 & 1.20 \\
\hline $300-400$ & 23 & 48 & 1.15 & $300-400$ & 47 & 62 & 0.80 \\
\hline $400-500$ & 18 & 22 & 0.65 & $400-500$ & $* 9$ & 4 & $* 0.28$ \\
\hline $500-600$ & 13 & 19 & 0.79 & $500-600$ & 20 & 11 & 0.36 \\
\hline$\geq 600$ & 64 & 26 & 0.24 & $\geq 600$ & 46 & 24 & 0.38 \\
\hline
\end{tabular}

$2 *$ Sample size caution: category contains less than $5 \%$ of relevant sample length 
These crash rates show the relative crash risk that has been experienced for different characteristic categories. As would be expected wider lanes have lower crash rates than narrower lanes, except for the narrowest lane category $(9 \mathrm{ft})$. The fact that 9 -ft lanes have experienced lower crash rates than 10- $\mathrm{ft}$ lanes may be evidence that some unseen factor(s) on 9-ft lanes (e.g. drivers choosing lower speeds on these narrow lanes) are effecting the crash rates. Also note that 9-ft lanes are not very common in the sample and the small sample size (approximately 26 miles) is an indication that this rate is less reliable than the other lane width category crash rates.

A similar phenomena can be observed with shoulder width crash rates. Narrow shoulders (and no shoulders especially) experience higher crash rates than the existence of shoulders up to 5 feet. Shoulders 6 feet and wider show increased crash rates compared to 4- and 5-ft shoulders, which again could be evidence of unseen factors (e.g. drivers choosing higher speeds on these wide total pavement widths) or understood that small samples sizes for shoulders 6 feet and wider could mean that these rates are less reliable than the other shoulder width categories.

In general, lower driveway densities tend to have lower crash rates compared to higher driveway densities. Similarly, lower grades tend to have lower crash rates than higher grades and flatter side slopes tend to have lower crash rates than steeper side slopes. The amount of fixed objects near the roadway doesn't appear to have an obvious trend with crash rate, and is also hindered by 2 of the 5 categories having small sample sizes.

\section{Regression and Correlation}

Multivariate linear regression was also performed for the sample using the independent variables: lane width, shoulder width, grade, degree of curvature, side slope rating, fixed object rating, guardrail presence, vertical curve presence, and driveway density to better understand possible relationships between these independent variables and two separate dependent variables: 1) crash rate and 2) crash severity rate.

This project was initiated with the knowledge that crashes are random events and identifying hazardous locations based on crash experience requires a crash frequency that is unlikely to be observed on low-volume roads. The regression analysis results reflect this fact. The overall model R-square value (0.072) for the crash rate analysis is small indicating that these independent variables don't account for any considerable portion of the observed crash rate variability. The low F significance number (1.7E-213) shows that this regression was not obtained by chance and was generated using a large sample size. All nine independent variables were found to be statistically significant at the $90 \%$ confidence level for crash rate. The signs $(+$ or -$)$ of the regression coefficients of most of these variables suggest logical relationships with the dependent variable (i.e. crash rate). Specifically, increases in lane width correspond to decreases in crash rate and increases in side slope rating, fixed object rating, driveway density, degree of curvature, and grade all correspond to increases in crash rate. The presence of guardrail corresponds to a reduction in crash rate. The presence of vertical curves also corresponds to reductions in crash rate, a result that may be counterintuitive. Similarly, an increase in shoulder width corresponds to increases in crash rate which seems counterintuitive, but somewhat in agreement with the individual crash rate analysis for shoulder widths above $5 \mathrm{ft}$.

The regression analysis was also performed using the dependent variable crash severity rate. The crash severity rate regression (weighted using equivalent PDO crash cost estimates from the Highway Safety Manual - HSM) showed similar results as the crash rate regression analysis. The severity rate R-square value (0.005) is also small indicating that the independent variables don't account for any considerable portion of the observed crash severity rate variability. Again 
the F significance number (5.1E-11) is small reflecting that this regression was not obtained by chance and was generated using a large sample size. Six of the independent variables (fixed object rating, guardrail presence, vertical curve presence, side slope rating, lane width, and shoulder width) were found to be statistically significant at the $90 \%$ confidence level for crash severity rate. The regression coefficients show that increases in fixed object rating correspond to increases in crash severity which is expected. Also the presence of guardrail corresponds to a reduction in crash severity which is also expected. Vertical curve presence corresponds to reduced crash severity which seems counterintuitive. Increased lane width corresponds to increased crash severity, which may be related to the fact that wider lanes may result in higher operating speeds on these highway segments, and thus more severe crashes. Lastly, increases in shoulder width correspond to reduced crash severity, a pattern that is expected given the wider recovery area for errant and out-of-control vehicles.

Correlation analysis results for crash rate and severirty rate are shown in Table 2 where $\mathrm{Cr}$ $\mathrm{R}$ is crash rate, $\mathrm{Sv} \mathrm{R}$ is severity rate, $\mathrm{LW}$ is lane width, $\mathrm{SW}$ is shoulder width, $\mathrm{SS}$ is side slope rating, FO is fixed object rating, GR is guardrail presence, $\mathrm{G}$ is grade, $\mathrm{VC}$ is vertical curve presence, DD is driveway density, and DC is degree of curvature. Correlations of \pm 0.10 or greater are bold.

TABLE 3 Correlation Results

\begin{tabular}{|l|r|r|r|r|r|r|r|r|r|r|r|}
\hline & Cr R & \multicolumn{1}{|c|}{ Sv R } & \multicolumn{1}{c|}{ LW } & \multicolumn{1}{c|}{ SW } & \multicolumn{1}{c|}{ SS } & FO & GR & G & VC & DD & DC \\
\hline Cr R & 1 & & & & & & & & & & \\
\hline Sv R & -- & 1 & & & & & & & & & \\
\hline LW & $\mathbf{- 0 . 1 9}$ & -0.01 & 1 & & & & & & & & \\
\hline SW & $\mathbf{- 0 . 1 0}$ & -0.03 & $\mathbf{0 . 4 4}$ & 1 & & & & & & & \\
\hline SS & $\mathbf{0 . 1 0}$ & 0.00 & -0.06 & $\mathbf{- 0 . 1 6}$ & 1 & & & & & & \\
\hline FO & $\mathbf{0 . 1 3}$ & 0.05 & $\mathbf{- 0 . 3 3}$ & $\mathbf{- 0 . 3 0}$ & $\mathbf{0 . 3 2}$ & 1 & & & & & \\
\hline GR & 0.00 & -0.01 & $\mathbf{0 . 1 0}$ & 0.05 & $\mathbf{0 . 3 1}$ & $\mathbf{0 . 1 5}$ & 1 & & & & \\
\hline G & 0.06 & 0.01 & -0.05 & -0.03 & 0.06 & 0.06 & 0.02 & 1 & & & \\
\hline VC & 0.07 & -0.01 & $\mathbf{- 0 . 2 3}$ & $\mathbf{- 0 . 2 0}$ & -0.02 & $\mathbf{0 . 1 2}$ & -0.05 & 0.04 & 1 & & \\
\hline DD & $\mathbf{0 . 1 0}$ & 0.00 & $\mathbf{- 0 . 2 2}$ & $\mathbf{- 0 . 2 6}$ & -0.05 & $\mathbf{0 . 1 0}$ & -0.05 & -0.02 & $\mathbf{0 . 1 3}$ & 1 & \\
\hline DC & $\mathbf{0 . 2 0}$ & 0.01 & $\mathbf{- 0 . 3 2}$ & $\mathbf{- 0 . 2 5}$ & $\mathbf{0 . 1 9}$ & $\mathbf{0 . 2 3}$ & 0.04 & $\mathbf{0 . 1 1}$ & $\mathbf{0 . 1 2}$ & -0.01 & 1 \\
\hline
\end{tabular}

Crash rate is correlated to some degree with the geometric and roadside features. As would be expected, increases in lane width and shoulder width are correlated with lower crash rates and increases in the side slope rating, fixed object rating, driveway density, and degree of curvature are correlated with higher crash rates. It is also evident that certain independent variable are somewhat correlated with each other. For instance, lane width is positively correlated with shoulder width indicating that roads with wider lanes tend to also have wider shoulders.

Severity rate has only very small correlations with the geometric and roadside features which may be a result of the equivalent PDO severity weights used from the HSM. Multipliers, which are based on comprehensive crash cost estimates, range from approximately 6 (for injury $\mathrm{C}$ crashes) up to 568 (for fatal crashes). These large distortions coupled with low traffic volumes which result in lower crash frequencies may contribute to the very weak correlations with crash severity rates. 


\section{DISCUSSION AND CONCLUSIONS}

Using a large sample of geometric and roadside features data in combination with traffic volumes and 10 years of crash data has allowed for meaningful crash risk deductions to be drawn for a setting in which low traffic volumes have typically impeded many quantitative safety efforts. The results of this effort (especially the crash rate analysis) show which characteristics on low-volume Oregon roads correspond with certain crash rates. For this sample, crashes are $64 \%$ more likely (per VMT) on 10-ft lanes than 12-ft lanes. Crashes are $83 \%$ more likely when no shoulder is present compared to having 4-ft shoulders. Crashes are 10 times more likely on curves with degree of curvature 30 or higher compared to curves with degree of curvature less than 5 .

The results of this effort are part of a larger project that combines this analysis with other efforts to ultimately define a crash risk index and evaluate the cost effectiveness of countermeasures related to the geometric and roadside features considered herein. Future work that could add value to this effort could include obtaining larger populations of certain sample types in order to have more reliable results for those categories that currently have small sample sizes (ie. 9-ft lanes, 6+ ft shoulders, etc.). While these results are most applicable to Oregon's lowvolume roads, other states and agencies with similar road types and traffic conditions may find value in the results and/or the process to quantify crash risks. These results can be used to proactively identify potentially risky road segments that may be unidentified using traditional methods which often require a localized crash frequency that may be greater than what is realistic given low traffic volumes. 


\section{ACKNOWLEDGEMENTS}

The authors would like to acknowledge the financial support to this project by the Oregon Department of Transportation. The authors would also like to thank the project technical panel for their support and help in data collection and other project tasks. 


\section{REFERENCES}

1. National Highway Traffic Safety Administration. Traffic Safety Facts 2013 Data: Rural/ Urban Comparison. Publication DOT HS 812 181. US Department of Transportation, 2015.

2. National Highway Traffic Safety Administration. Fatality Analysis Reporting System (FARS) Data Query Tool, 2013 Data. Gathered June, 2015.

3. U.S. Department of Transportation, Office of Highway Policy Information. Highway Statistics 2013. http://www.fhwa.dot.gov/policyinformation/statistics/2013/vm2.cfm

4. Cenek, P., Davies, R., and Henderson, R. Crash Risk Relationships for Improved Road Safety Management. Publication 488. New Zealand Transport Agency, 2012.

5. Garber, N. and Kassebaum, E. Evaluation of Crash Rates and Causal Factors for High-Risk Locations on Rural and Urban Two-Lane Highways in Virginia. Publication FHWA/VTRC 09-R1. Virginia Transportation Research Council, 2008.

6. Gross, F., Jovanis, P., and Eccles, K. Safety Effectiveness of Lane and Shoulder Width Combinations on Rural, Two-Lane, Undivided Roads. In Transportation Research Record: Journal of the Transportation Research Board, No. 2103, Transportation Research Board of the National Academies, Washington, D.C., 2009, pp 42-49.

7. McLean, J., Veith, G., and Turner, B. Road Safety Engineering Risk Assessment Part 1: Relationships Between Crash Risk and Standards of Geometric Design Elements. Publication AP-T146/10. Austroads, 2010.

8. Peng, Y., Geedipally, S., Lord, D. Effect of Roadside Features on Single-Vehicle Roadway Departure Crashes on Rural Two-Lane Roads. In Transportation Research Record: Journal of the Transportation Research Board, No. 2309, Transportation Research Board of the National Academies, Washington, D.C., 2012, pp 21-29.

9. Anderson, I. and Krammes, R. Speed Reduction as a Surrogate for Accident Experience at Horizontal Curves on Rural Two-Lane Highways. In Transportation Research Record: Journal of the Transportation Research Board, No. 1701, Transportation Research Board of the National Academies, Washington, D.C., 2000, pp 86-94.

10. Karlafis, M. and Golias, I. Effects of Road Geometry and Traffic Volumes on Rural Roadway Accident Rates. In Accident Analysis and Prevention, Vol. 34, 2002, pp. 357-365.

11. Polus, A., Pollatshek, M., and Farah, H. Impact of Infrastructure Characteristics on Road Crashes on Two-Lane Highways. In Traffic Injury Prevention, Vol. 6, 2005, pp 240-247.

12. Watson Jr., D., Al-Kaisy, A., and Anderson, N. Examining the Effect of Speed, Roadside Features, and Roadway Geometry on Crash Experience Along a Rural Corridor. In Journal of Modern Transportation, 2014. 